\title{
Cognitive function and number of teeth in a community-dwelling population in Japan
}

\author{
Yuki Saito ${ }^{1}$, Norio Sugawara ${ }^{2}$, Norio Yasui-Furukori ${ }^{2}$, Ippei Takahashi ${ }^{3}$, Shigeyuki Nakaji ${ }^{3}$ and Hiroto Kimura ${ }^{1}$
}

\begin{abstract}
Background: It has been reported that oral health is poor in elderly populations and is associated with poor cognition and dementia. The objective of this study was to examine the association between tooth loss and cognitive function in a community-dwelling population in Japan.

Methods: We examined the association between tooth loss and cognitive function in 462 Japanese communitydwelling individuals. The Mini-Mental State Examination (MMSE) was employed to measure global cognitive status. A multiple logistic regression analysis, with both crude and adjusted conditions for confounding factors, was used to assess the relationship between poor cognition and the number of remaining teeth.

Results: The overall prevalence of poor cognition (MMSE $\leq 23$ ) in this study population was $5.6 \%$. Subjects with poor cognition were significantly older, less educated, scored lower in intellectual activity, and had fewer remaining teeth than those with normal cognition. According to the multiple logistic regression analysis, a lower number of teeth $(0-10)$ was found to be a significant independent risk factor $(O R=20.21,95 \%$ confidence interval $=2.20$ to 185.47) of cognitive impairment.

Conclusions: This cross-sectional study on a Japanese community-dwelling population revealed relationships between tooth loss and cognitive function. However, the interpretation of our results was hampered by a lack of data, including socioeconomic status and longitudinal observations. Future research exploring tooth loss and cognitive function is warranted.
\end{abstract}

\section{Background}

Age-related cognitive impairment is an early sign of clinical dementia and has been reported to contribute to disability [1], morbidity [2], and mortality [3]. Recent community-based surveys in Japan showed that the prevalence of mild cognitive impairment and dementia were $23.4 \%$ and $16.4 \%$, respectively [2]. The identification of clinical markers predicting cognitive impairment in elderly individuals is often considered useful in easing the public health burden of poor cognition.

Many factors may contribute to cognitive impairment in older adults, including hypertension, cardiovascular disease, diabetes, dyslipidemia, and lifestyle factors such as smoking, alcohol, and diet [4]. In addition, education, exercise, and active social engagement may be protective factors [4]. However, the abovementioned factors are

\footnotetext{
* Correspondence: nsuga3@yahoo.co.jp

${ }^{2}$ Department of Neuropsychiatry, Hirosaki University School of Medicine, Hirosaki 036-8562, Japan

Full list of author information is available at the end of the article
}

interrelated in a complex manner that is not completely understood.

Tooth loss has been implicated to be associated with poor cognitive function in some studies of elderly populations. Using data from a cross-sectional Health Survey for England, Stewart et al. found that tooth loss was significantly associated with cognitive impairment even after adjusting for covariates in a community population [5]. They also showed that $40.4 \%$ of the community samples and $67.9 \%$ of the home care samples were edentulous. In addition, the Nun Study from the USA showed that patients with a low number of teeth had an increased risk of dementia based on longitudinal dental records [6].

The aim of the present study was to determine whether there is an association between tooth loss and cognitive function. For the evaluation of cognitive function, we employed the Mini-Mental State Examination (MMSE). Furthermore, we investigated the risk factors

\section{Biomed Central}


for tooth loss in a community-dwelling population in Japan.

\section{Methods}

\section{Participants}

The subjects consisted of 462 volunteers (163 males and 299 females, all 60 years old or over) who participated in the Iwaki Health Promotion Project in 2012. The data collection for this study was approved by the Ethics Committee of Hirosaki University School of Medicine, and all subjects had provided written informed consent before participating in the study. The demographic (age, gender, education level) and lifestyle (smoking, drinking) data and medical history were obtained from self-report questionnaires and interviews.

\section{Procedure}

A dental examination was performed by two dentists under artificial lighting, with both the dentist and the subject in a seated position. The teeth present were defined as healthy, carious, or treated.

The MMSE was administered to all participants to measure their global cognitive status. This test assesses orientation to place and time, short-term memory, episodic long-term memory, subtraction ability, ability to construct a sentence, and oral language ability. The maximum score was set at 30 , and poor cognition was defined as a score less than 23 [7].

The ability to perform activities of daily living was evaluated using the Tokyo Metropolitan Institute of Gerontology Index of Competence (TMIG-IC), a multidimensional 13-item scale [8]. The TMIG-IC was developed to measure the functional capacity of an independently living elderly and is composed of three competencies: instrumental self-maintenance (five items), intellectual activity (four items), and social role (four items). The TMIG-IC was used in previous studies to examine the functional capacity of community-dwelling Japanese elderly [9].

The Japanese version of the Center for Epidemiologic Studies Depression Scale (CES-D) [10,11] was administered to all of the participants to measure their depression symptoms. The CES-D is a 20 -item self-report measure that focuses on depression symptoms during the week prior to administering the questionnaire. The maximum score on this scale is 60 , and depression was considered to be present when a subject had a CES-D score of 16 or more.

\section{Statistical analysis}

Student's unpaired $t$ test (for continuous variables) or the chi-square test (for categorical variables) was used to compare subjects with and without poor cognition. A logistic regression analysis with both crude and adjusted conditions for confounding factors (age, gender, level of education, smoking status, habitual alcohol intake, positive history of diabetes mellitus, hypertension, cancer, TMIG-IC score, and CES-D total score) was used to assess the relationship between poor cognition and the number of remaining teeth. Additionally, a multiple linear regression analysis was applied to determine the factors associated with the number of teeth lost in a community-dwelling population. A $p$ value $<0.05$ was considered to be statistically significant. The data were analyzed using the PASW Statistics PC software for Windows, version 18.0.0 (SPSS Inc., Chicago, IL, USA).

\section{Results}

\section{Sample characteristics}

The subjects were divided into two groups according to their MMSE scores (poor cognition, MMSE $\leq 23, n=26$; control, MMSE $\geq 24, n=436$ ). The clinical characteristics

Table 1 Demographic characteristics of the subjects

\begin{tabular}{|c|c|c|}
\hline & $\begin{array}{l}\text { Poor cognition } \\
\quad(n=26)\end{array}$ & $\begin{array}{c}\text { Control } \\
(n=436)\end{array}$ \\
\hline MMSE* $^{*}$ & $21.0 \pm 2.0$ & $28.6 \pm 1.7$ \\
\hline Age (years)* & $73.7 \pm 7.9$ & $68.3 \pm 6.2$ \\
\hline Gender & $\begin{array}{l}\text { Male } 12, \\
\text { female } 14\end{array}$ & $\begin{array}{c}\text { Male } 151, \\
\text { female } 285\end{array}$ \\
\hline Level of education (years)* & $8.7 \pm 1.5$ & $10.8 \pm 1.9$ \\
\hline \multicolumn{3}{|l|}{ Smoking status } \\
\hline No & 18 & 339 \\
\hline Current & 2 & 31 \\
\hline Previous & 6 & 66 \\
\hline \multicolumn{3}{|l|}{ Habitual alcohol intake } \\
\hline No & 14 & 273 \\
\hline Current & 11 & 149 \\
\hline Previous & 1 & 14 \\
\hline \multicolumn{3}{|l|}{ Positive history of } \\
\hline Diabetes mellitus & $3(11.5 \%)$ & $44(10.1 \%)$ \\
\hline Hypertension & $13(50.0 \%)$ & $201(46.1 \%)$ \\
\hline Cancer & $3(11.5 \%)$ & $34(7.8 \%)$ \\
\hline \multicolumn{3}{|l|}{ TMIG-IC score } \\
\hline Instrumental self-maintenance & $4.6 \pm 0.8$ & $4.9 \pm 0.3$ \\
\hline Intellectual activity* & $2.9 \pm 1.1$ & $3.6 \pm 0.7$ \\
\hline Social role & $3.4 \pm 1.0$ & $3.7 \pm 0.6$ \\
\hline CES-D total score & $11.9 \pm 7.1$ & $10.3 \pm 5.9$ \\
\hline Number of remaining teeth* & $5.8 \pm 7.3$ & $16.2 \pm 9.7$ \\
\hline Number of teeth lost* & $22.3 \pm 7.1$ & $11.9 \pm 9.6$ \\
\hline
\end{tabular}

Student's unpaired $t$ test for continuous variables or chi-square test for categorical variables was used to evaluate the differences between poor cognition (MMSE $\leq 23$ ) and control (MMSE $\geq 24)$. Values for the different tests are presented as mean \pm S.D. MMSE Mini-Mental State Examination, TMIG-IC Tokyo Metropolitan Institute of Gerontology Index of Competence, CES-D Center for Epidemiologic Studies for Depression scale. ${ }^{*} p<0.05$. 
of the subjects are listed in Table 1 . The subjects with poor cognition were significantly older and less educated, and they had lower TMIG-IC scores, fewer remaining teeth, and a higher amount of teeth lost compared with the control group. No other differences were observed in all of the other characteristics.

\section{Relationship between the number of remaining teeth and cognitive decline}

Table 2 presents the results of the logistic regression analysis used to assess the relationship between the number of remaining teeth and cognitive decline. After adjusting for confounding factors, 0-10 remaining teeth $(\mathrm{OR}=20.21,95 \%$ confidence interval $(\mathrm{CI})=2.20$ to 185.47) was shown to be an independent risk factor for cognitive decline. Under both crude and adjusted conditions, a higher level of education and a higher intellectual activity score (TMIG-IC) were consistently associated with a lower risk of cognitive impairment.

\section{Factors associated with the number of teeth lost}

The results of a multiple linear regression analysis that included age, gender, education level, smoking status, and habitual alcohol intake; positive history of diabetes mellitus, hypertension, and cancer; and TMIG-IC score, CES-D total score, and MMSE total score are shown in Table 3. Age, education level, current smoking status, positive history of diabetes mellitus, and MMSE total score were independently and significantly associated with the number of remaining teeth.

\section{Discussion}

This cross-sectional study was designed to evaluate the relationship between tooth loss and cognitive function in a community-dwelling Japanese population. Severe tooth loss (0-10 teeth remaining) was found to be significantly associated with poor cognitive function after adjusting for confounders. Furthermore, the number of teeth lost was significantly correlated with age, education level, current smoking status, positive history of diabetes, and MMSE total score in a community-dwelling population in Japan.

To date, some studies have shown a relationship between tooth loss and cognitive function in communitydwelling elderly individuals. In a study on a Swedish population of individuals aged 35 to 85 years [12],

Table 2 Risk factors associated with having lower MMSE scores $(\leq 23)$ as estimated by logistic regression analysis

\begin{tabular}{|c|c|c|c|c|}
\hline Parameter & Crude odds ratio (mean $(95 \% \mathrm{Cl})$ ) & $p$ value & Adjusted odds ratio (mean $(95 \% \mathrm{CI})$ ) & $p$ value \\
\hline Age (years) & $1.12(1.06-1.19)$ & $<0.001$ & $0.99(0.91-1.08)$ & 0.847 \\
\hline Male & $1.62(0.73-3.59)$ & 0.236 & $2.98(0.71-12.53)$ & 0.136 \\
\hline Level of education (years) & $0.53(0.41-0.68)$ & $<0.001$ & $0.52(0.35-0.78)$ & $<0.01$ \\
\hline \multicolumn{5}{|l|}{ Smoking status } \\
\hline No & 1.00 & & 1.00 & \\
\hline Current & $1.22(0.27-5.48)$ & 0.800 & $0.88(0.11-6.81)$ & 0.904 \\
\hline Previous & $1.71(0.66-4.48)$ & 0.273 & $1.89(0.44-8.20)$ & 0.395 \\
\hline \multicolumn{5}{|l|}{ Habitual alcohol intake } \\
\hline No & 1.00 & & 1.00 & \\
\hline Current & $1.44(0.64-3.25)$ & 0.381 & $0.75(0.19-2.98)$ & 0.683 \\
\hline Previous & $1.39(0.17-11.36)$ & 0.757 & $1.08(0.07-15.81)$ & 0.954 \\
\hline \multicolumn{5}{|l|}{ Positive history of } \\
\hline Diabetes mellitus & $1.16(0.34-4.03)$ & 0.813 & $0.36(0.06-2.14)$ & 0.259 \\
\hline Hypertension & $1.17(0.53-2.58)$ & 0.699 & $0.73(0.23-2.28)$ & 0.589 \\
\hline Cancer & $1.54(0.44-5.40)$ & 0.498 & $1.74(0.35-8.73)$ & 0.503 \\
\hline \multicolumn{5}{|l|}{ TMIG-IC score } \\
\hline Instrumental self-maintenance & $0.35(0.18-0.69)$ & $<0.01$ & $0.58(0.20-1.75)$ & 0.336 \\
\hline Intellectual activity & $0.38(0.25-0.57)$ & $<0.001$ & $0.57(0.33-0.98)$ & $<0.05$ \\
\hline Social role & $0.60(0.37-0.99)$ & $<0.05$ & $0.55(0.29-1.06)$ & 0.074 \\
\hline CES-D total score & $1.04(0.98-1.11)$ & 0.198 & $0.98(0.90-1.08)$ & 0.723 \\
\hline \multicolumn{5}{|l|}{ Number of remaining teeth } \\
\hline $22-32$ & 1.00 & & 1.00 & \\
\hline $11-21$ & $7.34(0.85-63.57)$ & 0.070 & $3.50(0.32-38.25)$ & 0.305 \\
\hline $0-10$ & $27.33(3.62-206.21)$ & $<0.01$ & $20.21(2.20-185.47)$ & $<0.01$ \\
\hline
\end{tabular}


Table 3 Multiple regression analysis of tooth loss

\begin{tabular}{|c|c|c|c|c|c|}
\hline Parameter & $\begin{array}{c}\text { Partial } \\
\text { regression } \\
\text { coefficient }\end{array}$ & $\begin{array}{l}\text { Standard } \\
\text { error }\end{array}$ & $t$ value & Beta & $p$ value \\
\hline Age (years) & 0.476 & 0.075 & 0.311 & 6.375 & $<0.001$ \\
\hline Male & -0.873 & 1.188 & -0.043 & -0.734 & 0.463 \\
\hline $\begin{array}{l}\text { Level of education } \\
\text { (years) }\end{array}$ & -0.787 & 0.245 & -0.158 & -3.217 & $<0.01$ \\
\hline \multicolumn{6}{|l|}{ Smoking status } \\
\hline Current & 4.657 & 1.746 & 0.123 & 2.667 & $<0.01$ \\
\hline Previous & 2.259 & 1.320 & 0.084 & 1.712 & 0.088 \\
\hline \multicolumn{6}{|l|}{$\begin{array}{l}\text { Habitual alcohol } \\
\text { intake }\end{array}$} \\
\hline Current & -1.728 & 1.126 & -0.084 & -1.535 & 0.126 \\
\hline Previous & -1.883 & 2.462 & -0.034 & -0.765 & 0.445 \\
\hline \multicolumn{6}{|l|}{ Positive history of } \\
\hline Diabetes mellitus & 3.100 & 1.398 & 0.095 & 2.218 & $<0.05$ \\
\hline Hypertension & 0.412 & 0.885 & 0.021 & 0.466 & 0.642 \\
\hline Cancer & 1.994 & 1.514 & 0.056 & 1.317 & 0.189 \\
\hline \multicolumn{6}{|l|}{ TMIG-IC score } \\
\hline $\begin{array}{l}\text { Instrumental } \\
\text { self-maintenance }\end{array}$ & 1.863 & 1.245 & 0.067 & 1.497 & 0.135 \\
\hline $\begin{array}{l}\text { Intellectual } \\
\text { activity }\end{array}$ & -0.679 & 0.653 & -0.049 & -1.041 & 0.299 \\
\hline Social role & 0.573 & 0.658 & 0.038 & 0.870 & 0.385 \\
\hline CES-D total score & 0.073 & 0.070 & 0.044 & 1.035 & 0.301 \\
\hline MMSE total score & -0.490 & 0.189 & -0.124 & -2.592 & $<0.05$ \\
\hline
\end{tabular}

edentulous individuals showed lower MMSE scores than those with natural teeth. Even after matching for gender, age, social variables, diseases, stress, and MMSE scores, the cognitive disadvantage of the edentulous group was still apparent. The national Finnish data on individuals aged 55 years and older [13] also showed that individuals with low MMSE scores (0-9) often have no teeth or dentures and less frequently have good denture hygiene than those with high MMSE scores (12-16). In addition, a population-based study on individuals aged 60 to 79 years in Germany [14] reported a significant association between low MMSE scores and the number of remaining teeth after excluding subjects with a history of stroke, traumatic brain injury, Parkinson's disease, multiple sclerosis, or epilepsy.

Several explanations have been hypothesized for the association between poor cognitive function and tooth loss. Periodontal disease, a chronic infection caused by bacteria in the tissue surrounding the teeth, is a common cause of tooth loss in the elderly [15]. The localized inflammatory reaction associated with periodontal disease may lead directly or indirectly to a state of chronic low-grade systemic inflammation associated with raised levels of cytokines [16,17]. Periodontal disease may contribute to cognitive impairment through systemic inflammation [18,19]. Another explanation is that a reduced number of teeth may be associated with nutritional deficits, especially in relation to B vitamins $[20,21]$, which may also play a role in cognitive decline. A third explanation is that the association observed in this study may be due to some unmeasured or unobserved confounding factor. Vascular risk factors [22] and low socioeconomic status [23] may have played a role in the development of cognitive decline. However, assessment of the abovementioned factors was limited in this study, and we cannot rule out the effects of underlying factors. Finally, reversed causality may also be an explanation for our results. Individuals with poor cognitive function may be more likely to have (or to develop) poor oral health because they have a lower ability to perform proper tooth brushing, manage dentures, and use dental-related medications [24].

In this study, we found a relationship between the number of teeth lost and diabetes. Previous studies have shown a relationship between diabetes and tooth loss $[25,26]$. Long-standing hyperglycemia could lead to the formation of advanced glycation end products (AGEs) [27]. AGEs can transform macrophages into cells with a destructive phenotype, leading to the production of high levels of cytokines and increasing the permeability of the endothelium [28]. Patients with diabetes have these predispositions, which could cause infections and an impaired healing process.

We also found an association between smoking and the number of teeth lost. Substances in tobacco smoke can destroy the supporting tissue of the teeth by causing the dysfunction of gingival fibroblasts, a decrease in microcirculatory function, and immune system deficiency [29-31]. In addition, an impaired ability to repair damaged tissue may aggravate the periodontal destruction in smokers.

There are several limitations to our study. First, the cross-sectional nature of the study does not allow for causal assumptions regarding the relationship between tooth loss and poor cognitive function. Future studies with longitudinal designs are needed to investigate these associations. Second, we administered only the MMSE for the assessment of cognitive function. Although the MMSE is suitable for the screening of some cognitive functions, including orientation to place and time, shortterm memory, episodic long-term memory, subtraction ability, and attention, the MMSE score does not always reflect the cognitive function exactly; it is known to be influenced by the education level of the subject. Third, several potential confounding factors, such as socioeconomic level and denture usage, were not assessed in our study. Fourth, as all of the participants were 
volunteers who were interested in their health, they may have been healthier than the general population. Thus, the cognitive function and tooth number of members of the community who were not in the study may vary from those of the study participants. This 'selection bias' must also be considered in studies on community populations. Finally, as our sample size was relatively small, we cannot completely rule out beta error as the cause of our failure to detect associations between tooth loss and cognitive function.

\section{Conclusions}

This cross-sectional study on a Japanese communitydwelling population revealed relationships between tooth loss and cognitive function. However, the interpretation of our results was hampered by a lack of data, including socioeconomic status and longitudinal observations. Therefore, future research exploring tooth loss and cognitive function is warranted.

\section{Competing interests}

The authors declare that they have no competing interests.

\section{Authors' contributions}

YS conceived of the study and wrote the initial draft of the manuscript. NS designed the study, conducted the statistical analyses, interpreted the data, and assisted in drafting the manuscript. NYF contributed to the study design and interpretation of the results and had full access to all of the data in the study. IT and SN participated in the data collection. HK took responsibility for the integrity of the data and the accuracy of the data analysis. All authors read and approved the final manuscript.

\section{Acknowledgements}

The authors would like to thank all of their coworkers in this study for their skillful contributions to the collection and management of the data.

\section{Author details}

${ }^{1}$ Department of Oral and Maxillofacial Surgery, Hirosaki University School of Medicine, Hirosaki 036-8562, Japan. ²Department of Neuropsychiatry, Hirosaki University School of Medicine, Hirosaki 036-8562, Japan. ${ }^{3}$ Department of Social Medicine, Hirosaki University School of Medicine, Hirosaki 036-8562, Japan.

Received: 29 April 2013 Accepted: 5 June 2013

Published: 24 June 2013

\section{References}

1. Gill TM, Richardson ED, Tinetti ME: Evaluating the risk of dependence in activities of daily living among community-living older adults with mild to moderate cognitive impairment. J Gerontol A Biol Sci Med Sci 1995, 50:235-241.

2. Weiler PG, Lubben JE, Chi I: Cognitive impairment and hospital use. Am J Public Health 1991, 81:1153-1157.

3. Liu IY, LaCroix AZ, White LR, Kittner SJ, Wolf PA: Cognitive impairment and mortality: a study of possible confounders. Am J Epidemiol 1990, 132:136-143.

4. Qiu C, De Ronchi D, Fratiglioni L: The epidemiology of the dementias: an update. Curr Opin Psychiatry 2007, 20:380-385.

5. Stewart $R$, Hirani V: Dental health and cognitive impairment in an English national survey population. J Am Geriatr Soc 2007, 55:1410-1414.

6. Stein PS, Desrosiers M, Donegan SJ, Yepes JF, Kryscio RJ: Tooth loss, dementia and neuropathology in the Nun study. J Am Dent Assoc 2007, 138:1314-1322.
7. Folstein MF, Folstein SE, McHugh PR: "Mini-mental state". A practical method for grading the cognitive state of patients for the clinician. J Psychiatr Res 1975, 12:189-198.

8. Koyano W, Shibata H, Nakazato K, Haga H, Suyama Y: Measurement of competence: reliability and validity of the TMIG-index of competence. Arch Gerontol Geriatr 1991, 13:103-116.

9. Ishizaki T, Watanabe S, Suzuki T, Shibata H, Haga H: Predictors for functional decline among nondisabled older Japanese living in a community during a 3-year follow-up. J Am Geriatr Soc 2000, 48:1424-1429.

10. Radloff LS: The CES-D scale: a self-report depression scale for research in the general population. Appl Psychol Meas 1977, 1:385-401.

11. Shima S, Shikano T, Kitamura T: New self-rating scales for depression [in Japanese]. Clin Psychiatry 1985, 27:717-723.

12. Bergdahl M, Habib R, Bergdahl J, Nyberg L, Nilsson LG: Natural teeth and cognitive function in humans. Scand J Psychol 2007, 48:557-565.

13. Syrjälä AM, Ylöstalo $P$, Sulkava R, Knuuttila M: Relationship between cognitive impairment and oral health: results of the Health 2000 Health Examination Survey in Finland. Acta Odontol Scand 2007, 65:103-108.

14. Grabe HJ, Schwahn C, Völzke H, Spitzer C, Freyberger HJ, John U, Mundt T, Biffar R, Kocher T: Tooth loss and cognitive impairment. J Clin Periodontol 2009, 36:550-557.

15. Pihlstrom BL, Michalowicz BS, Johnson NW: Periodontal diseases. Lancet 2005, 366:1809-1820.

16. Craig RG, Yip JK, So MK, Boylan RJ, Socransky SS, Haffajee AD: Relationship of destructive periodontal disease to the acute-phase response. J Periodontol 2003, 74:1007-1016.

17. Bretz WA, Weyant RJ, Corby PM, Ren D, Weissfeld L, Kritchevsky SB, Harris T, Kurella M, Satterfield S, Visser M, Newman AB: Systemic inflammatory markers, periodontal diseases, and periodontal infections in an elderly population. J Am Geriatr Soc 2005, 53:1532-1537.

18. Schmidt R, Schmidt H, Curb JD, Masaki K, White LR, Launer LJ: Early inflammation and dementia: a 25-year follow-up of the Honolulu-Asia Aging Study. Ann Neurol 2002, 52:168-174.

19. Watts A, Crimmins EM, Gatz M: Inflammation as a potential mediator for the association between periodontal disease and Alzheimer's disease. Neuropsychiatr Dis Treat 2008, 4:865-876.

20. Tucker KL, Qiao N, Scott T, Rosenberg I, Spiro A 3rd: High homocysteine and low $B$ vitamins predict cognitive decline in aging men: the Veterans Affairs Normative Aging Study. Am J Clin Nutr 2005, 82:627-635.

21. $\mathrm{Yu} Y \mathrm{YH}, \mathrm{Kuo} H K$, Lai $Y L$ : The association between serum folate levels and periodontal disease in older adults: data from the National Health and Nutrition Examination Survey 2001/02. J Am Geriatr Soc 2007, 55:108-113.

22. Sugawara N, Yasui-Furukori N, Umeda T, Kaneda A, Sato Y, Takahashi I, Matsuzaka M, Danjo K, Nakaji S, Kaneko S: Comparison of ankle-brachial pressure index and pulse wave velocity as markers of cognitive function in a community-dwelling population. BMC Psychiatry 2010, 10:46.

23. Jiang Y, Okoro CA, Oh J, Fuller DL: Sociodemographic and health-related risk factors associated with tooth loss among adults in Rhode Island. Prev Chronic Dis. in press.

24. Philip P, Rogers C, Kruger E, Tennant M: Oral hygiene care status of elderly with dementia and in residential aged care facilities. Gerodontology 2012, 29:e306-e311.

25. Kaur G, Holtfreter B, Rathmann W, Schwahn C, Wallaschofski H, Schipf S, Nauck M, Kocher T: Association between type 1 and type 2 diabetes with periodontal disease and tooth loss. J Clin Periodontol 2009, 36:765-774

26. Jimenez M, Hu FB, Marino M, Li Y, Joshipura KJ: Type 2 diabetes mellitus and 20 year incidence of periodontitis and tooth loss. Diabetes Res Clin Pract 2012, 98:494-500.

27. lacopino AM, Cutler CW: Pathophysiological relationships between periodontitis and systemic disease: recent concepts involving serum lipids. J Periodontol 2000, 71:1375-1384.

28. Hudson BI, Bucciarelli LG, Wendt T, Sakaguchi T, Lalla E, Qu W, Lu Y, Lee L, Stern DM, Naka Y, Ramasamy R, Yan SD, Yan SF, D'Agati V, Schmidt AM: Blockade of receptor for advanced glycation endproducts: a new target for therapeutic intervention in diabetic complications and inflammatory disorders. Arch Biochem Biophys 2003, 419:80-88. 
29. Hanioka T, Ojima M, Tanaka K, Matsuo K, Sato F, Tanaka H: Causal assessment of smoking and tooth loss: a systematic review of observational studies. BMC Public Health 2011, 11:221.

30. U.S. Department of Health and Human Services: The Health Consequences of Smoking: A Report of the Surgeon General. Atlanta: U.S: Department of Health and Human Services, Centers for Disease Control and Prevention, National Center for Chronic Disease Prevention and Health Promotion, Office on Smoking and Health; 2004.

31. Ojima M, Hanioka T: Destructive effects of smoking on molecular and genetic factors of periodontal disease. Tob Induc Dis 2010, 8:4.

doi:10.1186/1744-859X-12-20

Cite this article as: Saito et al: Cognitive function and number of teeth

in a community-dwelling population in Japan. Annals of General

Psychiatry 2013 12:20.

\section{Submit your next manuscript to BioMed Central and take full advantage of:}

- Convenient online submission

- Thorough peer review

- No space constraints or color figure charges

- Immediate publication on acceptance

- Inclusion in PubMed, CAS, Scopus and Google Scholar

- Research which is freely available for redistribution 